\title{
PROBLEMATIZANDO PRÁTICAS DE ENSINO E APRENDIZAGEM NA PLATAFORMA MOODLE: APROXIMAÇÕES COM A MODALIDADE HÍBRIDA
}

\section{Heloisa Brito de Albuquerque Costa}

- RESUMO: O objetivo deste artigo é realizar um estudo reflexivo-crítico das experiências de ensino realizadas na Plataforma Moodle nas disciplinas de didática do Curso de Letras Francês/Português da Universidade de São Paulo. Para isso, apresentaremos os fundamentos teóricos que embasaram este estudo, mais especificamente, as mudanças ocorridas com as Tecnologias da Informação e da Comunicação (TIC) e a Internet e seu impacto na cultura de aprendizagem (COLL; MONEREO, 2010; KENSKI, 2008). Trazemos também o quadro geral de modalidades de ensino decorrentes dessas transformaçóes na forma de ensinar e aprender, com destaque para a formação híbrida. (COLL; MONEREO, 2010; VALENTE, 2014; BACICH; TANZI NETO; TREVISANI, 2015). Em seguida, descreveremos as atividades do Moodle e, a partir dos dados observados, discutiremos os limites e possibilidades gerados por esse estudo em relação a outras modalidades de ensino. Por último, propomos alguns pontos que podem nortear novas açóes e pesquisas na área.

- PALAVRAS-CHAVE: Tecnologias. Modalidades de ensino virtual. Moodle. Ensino híbrido.

Dos anos 1990 até os dias de hoje, em diferentes situaçóes do nosso cotidiano de caráter pessoal, profissional e/ou acadêmico utilizamos a Internet e estamos em contato com tecnologias mediadas pelo computador ou smartphones ou tablets para realizar diversas ações como, por exemplo, consultas de naturezas diversas (informaçóes, e-mails, histórico escolar, entre outras), solicitação de serviços, comunicação por meio de chat ou por e-mail, cursos on-line, enfim, uma série de possibilidades que a Internet tornou possível nas últimas décadas. No caso das tecnologias móveis, como o telefone celular e o tablet, podemos nos conectar por meio de aplicativos a vários recursos on-line, o que nos possibilita também obter informaçōes, facilitar comunicaçóes, resolver problemas, otimizando assim nosso tempo e espaço.

Com recursos de som, de texto e de áudio, ferramentas de busca e outros recursos, a Internet permite obter em tempo real inúmeros dados úteis no nosso dia-a-dia, no trânsito, no trabalho, na escola, enfim, uma quantidade enorme de exemplos que nos mostram como as tecnologias estão presentes em nosso cotidiano. A todo o momento e

\footnotetext{
* USP - Universidade de São Paulo. Faculdade de Filosofia Letras e Ciências Humanas - Departamento de Letras Modernas. São Paulo - SP - Brasil. 05508-900 - heloisaalbuqcosta@usp.br
} 
de uma maneira bem rápida, novos recursos surgem e se incorporam às nossas atividades, transformando nossa forma de pensar, de trabalhar, de ensinar, de comunicar e de nos relacionarmos com o(s) outro(s). Trata-se, segundo Coll e Monereo (2010, p. 16), "[...] de um novo e complexo espaço global para a ação social e, por extensão, para o aprendizado e para a ação educacional".

Para Kenski (2008, p. 23-24), as Tecnologias de Informação e Comunicação (TIC) e a Internet não são meramente suportes. "Elas interferem no nosso modo de pensar, sentir, agir, de nos relacionarmos socialmente e adquirirmos conhecimentos. Criam uma nova cultura e um novo modelo de sociedade."

Coll e Monereo (2010) mencionam uma mudança de paradigma social que as TIC trazem para o mundo atual, ou seja, a passagem de uma lógica de consumo individual para uma lógica que privilegia o coletivo, a comunicação, o compartilhamento de informaçôes e interaçôes entre grupos para a busca de soluções a problemas de diferentes ordens.

Em um mundo em que as distâncias são cada vez mais reduzidas, as fronteiras desaparecem e os grandes problemas são compartilhados, cresce a mobilidade das pessoas, aumenta a heterogeneidade das comunidades e torna-se patente a necessidade de trabalhar conjuntamente para resolver problemas comuns. (COLL; MONEREO, 2010, p. 26).

Os autores salientam que há três conceitos que caracterizam essa mudança: adaptabilidade, mobilidade e cooperação. No mundo globalizado, a adaptabilidade das TIC se refere aos recursos disponíveis que sejam de fácil adaptação, com interfaces cada vez mais amigáveis e de fácil utilização; a segunda característica diz respeito à possibilidade de reduzir distâncias, tendo em vista o alto grau de mobilidade das pessoas no mundo de hoje. Com uma tecnologia móvel, a comunicação se dá quase que instantaneamente, o que torna possível resolver uma série de questôes de informação, comunicação e formação, esta última se considerarmos o aumento significativo de cursos à distância ou acesso a dispositivos on-line. A terceira característica, a cooperação, instaura uma nova cultura nas relaçôes entre os indivíduos que passam a desenvolver trabalhos de cooperação e colaboraçáo, envolvendo uma, duas pessoas ou toda uma comunidade. Este aspecto, no contexto educacional, é fundamental na medida em que é possível o compartilhamento de aprendizagens, conhecimentos e o desenvolvimento de competências no ambiente escolar ou acadêmico e também em outros contextos.

Mais especificamente no âmbito educacional, o impacto das TIC reforçam a ideia de imersão em "um novo espaço global para a ação social e, por extensão, para o aprendizado e para a ação educacional" (COLL; MONEREO, 2010, p. 15). Assim, no ensino e aprendizagem de um modo geral, professores e alunos, usuários da Internet têm à sua disposição um conjunto de tecnologias que modificam seus papeis dentro do contexto escolar/acadêmico, pois o papel centralizador do professor dá lugar a redes de 
conexão que os alunos podem estabelecer para a realização de tarefas. Além da interação em grupos mediada pelas TIC, os alunos têm condiçóes de se tornarem autores e produtores de conhecimentos que são compartilhados e difundidos.

Neste sentido, recursos digitais na sala de aula presencial como, por exemplo, a lousa digital, plataformas de ensino e aprendizagem ou ainda as tecnologias móveis como o celular, o tablet, podem ser usados para integrar atividades que contribuam para expandir, potencializar e otimizar o aprendizado dos alunos.

Mas, podemos afirmar que os professores e alunos compreendem o significado das TIC e da Internet para ensinar e aprender?

Esta questão é bem ampla e demandaria uma análise minuciosa de diferentes contextos de ensino, um estudo do perfil de professores e de alunos, das condiçóes estruturais de cada estabelecimento, entre outros aspectos. $\mathrm{O}$ fato que não podemos deixar de considerar é o impacto das transformações que as TIC e a Internet vêm provocando nos contextos escolares/acadêmicos, pois, uma vez presentes, demandam dos professores e alunos, reflexóes e ações sobre o que é aprender e ensinar com estes recursos.

$\mathrm{Na}$ Internet, a seleção de informaçôes, as conexôes e relaçôes com diversos links, a classificação e a síntese do que é encontrado, o armazenamento em um dispositivo on-line, por exemplo, exigem do aluno uma participaçáo mais ativa e autônoma, na medida em que ao navegar percorre caminhos não lineares e não aqueles definidos exclusivamente pelo professor.

A progressiva miniaturização e integração de tecnologias, junto com o desenvolvimento de plataformas móveis e da conexáo sem fio, permitirão que os alunos possam continuar avançando em sua formaçáo tendo acesso, a qualquer momento, por meio de seu celular, de agendas eletrônicas, computadores de bolso ou de outros dispositivos, a documentos, portfólios, fóruns, chats, questionários, webquests, weblogs, listas de discussão, etc. (COLL; MONEREO, 2010, p. 28).

Esta mudança de paradigma educacional nos leva a compreender, portanto, que a sala de aula presencial não está mais restrita a quatro paredes, tendo o professor como aquele que centraliza e transmite saberes. A sala de aula e seus participantes passam a ser o espaço no qual pode ser favorecida uma dinâmica mais participativa dos alunos que, além de mobilizarem conhecimentos prévios, podem construir outros em novos espaços interativos de aprendizagem em tempo real, síncrono ou assíncrono, com o auxílio das TIC e da Internet.

Para o professor, a contribuição se dá na organização de seu trabalho diário, na preparação de atividades, na integraçáo de mecanismos que promovam a expansáo do aprendizado do aluno e que alterem dinâmicas e estratégias na sala de aula.

A busca na Internet por meio de softwares específicos, a seleção de sites e informações para uma pesquisa ou a realização de atividades multimodais quando há a integração de texto, som e áudio, tarefas de leitura hipertextual ou ainda a organização de um 
espaço on-line para o compartilhamento de produção, trocas interativas em chats, fóruns de discussão ou em outras ferramentas como o dispositivo Evernote ${ }^{l}$ permite que professores e alunos estabeleçam diferentes canais de comunicação e compartilhamento de documentos orais ou escritos, imagens, vídeos, entre outros recursos.

Trata-se de uma nova cultura de ensino e aprendizagem que possibilita a construção de conhecimentos em um sistema em rede, rizoma, o compartilhamento de informaçóes, de espaços nos quais a participação é ativa de todos os envolvidos, ou seja, o que um realiza tem impacto direto na produção do outro e do coletivo como um todo.

Entender o desenvolvimento humano como uma exibição predeterminada de capacidades e habilidades pessoais, como simples atualizaçáo de potencialidades genéticas, levaria-nos a considerar as tecnologias como meros elementos contextuais que acompanham o amadurecimento do indivíduo. Pelo contrário, visto a partir de uma perspectiva construtivista que entende o desenvolvimento como a transformaçáo por meio do processo de troca entre organismo e ambiente físico e social, as tecnologias desempenham um papel essencial na definição dos processos evolutivos. (LALUEZA; CRESPO; CAMPS, 2010, p. 47).

Nas universidades brasileiras, nos Cursos de Letras, em particular, nas formações em Licenciatura, os currículos ainda não apresentam de forma expressiva a inclusão de disciplinas on-line (SANTOS, 2015) ou a inclusão no âmbito de disciplinas presenciais de temáticas que discutam as TIC.

Nesse sentido, é fundamental discutir o que estamos fazendo para a formação dos alunos de Letras-Licenciatura para formar o futuro professor de línguas capaz de compreender o uso das TIC na sala de aula, para poder pensar em atuar em ambientes virtuais de aprendizagem.

A imagem de um professor transmissor de informaçáo, protagonista central das trocas entre seus alunos e guardiáo do currículo começa a entrar em crise em um mundo conectado por telas de computador. Continuamente, aparecem grupos de estudantes que, através da Internet, colaboram e se ajudam em suas tarefas escolares com espantosa facilidade; Webs temáticas que tratam sobre qualquer tema de forma atualizada, com diferentes níveis de profundidade e, às vezes, permitindo acesso direto aos autores mais relevantes. (COLL; MONEREO, 2010, p. 31).

Diante de todo este panorama, interessa-nos aqui realizar um estudo reflexivo-crítico do que desenvolvemos nas disciplinas de didática em língua francesa do Curso de Letras

\footnotetext{
1 Evernote é um dispositivo de armazenamento e compartilhamento de dados, de documentos e textos orais e escritos, além de chats para interação on-line. Para outras informaçóes consultar: <https://evernote. com/intl/pt-br/>. Acesso em: 27 set. 2016.
} 
da Faculdade de Filosofia, Letras e Ciências Humanas da Universidade de São Paulo (FFLCH-USP), mais especificamente, nas disciplinas de "Aquisição e aprendizagem do Francês como Língua Estrangeira" e "Atividades de estágio em Francês", buscando, a partir de nossa experiência com a Plataforma Moodle, problematizar nossas práticas pedagógicas e direcionar nossas açóes para contribuir com a formação de professores.

Antes de passarmos à apresentação do que foi realizado nas disciplinas acima, consideramos necessário discorrer sobre as transformaçóes da Internet ao longo das últimas décadas, o que as TIC possibilitaram no ensino e aprendizagem de línguas estrangeiras para, em seguida, tratar das diferentes modalidades de ensino que encontramos hoje.

Tendo estes pressupostos explicitados, nosso objetivo é o de, a partir dos dados de nossas práticas no Moodle, apontar mudanças que possam orientar a formação do professor do século XXI.

\section{Internet e TIC: potencialidades, modalidades de ensino e mudanças na cultura de ensino e aprendizagem}

Para melhor compreender o impacto das TIC e da Internet no ensino e aprendizagem de línguas, é necessário apresentar as modificaçóes ocorridas com a Internet e as modalidades de ensino e aprendizagem desenvolvidas ao longo das últimas duas décadas (VALENTE, 2014; COLL; MONEREO, 2010).

Apresentaremos, primeiramente, os três estágios que caracterizam a Internet, segundo o que Coll e Monereo (2010) caracterizam como Sociedade da Informação.

Graças à interligação de diferentes computadores digitais e à internet chegamos, assim strictu sensu, à Sociedade da Informação, que poderíamos definir como um novo estágio de desenvolvimento das sociedades humanas, caracterizado, do ponto de vista das TIC, pela capacidade de seus membros para obter e compartilhar qualquer quantidade de informação de maneira praticamente instantânea, a partir de qualquer lugar e na forma preferida, e com custo muito baixo. (COLL; MONEREO, 2010, p. 20).

O primeiro estágio é a Web 1.0, compreendida como "um imenso repositório de conteúdos aos quais os usuários podem acessar para procurar e baixar arquivos" (COLL; MONEREO, 2010, p. 34), comparada a uma concepção de ensino e aprendizagem tradicional na qual o professor determina o que deve ser consultado e os alunos seguem orientaçóes para a leitura de arquivos.

Com o avanço das tecnologias, o espaço virtual se transforma e passamos a um momento no qual há a seleção, atualização da informação e uma dinâmica de colaboração e cooperação. É a Web 2.0. O uso da Internet permite o compartilhamento e organização de dados, definindo formas de interação e a construção de novas práticas 
de aprendizagem. As características da rede são: acesso a informaçóes das mais diversas fontes; recursos e conteúdos são ajustados às necessidades dos usuários; softwares livres; consulta a páginas da Web e documentos que podem ser integrados em outros espaços; organização colaborativa das informaçóes;

Ao colocar o destaque nos aplicativos, utilidades e serviços que permitem ao usuário criar e difundir seus próprios conteúdos, assim como na possibilidade de trocar, compartilhar e reutilizar os conteúdos criados pelo próprio usuário e por outros, a Web 2.0 abre perspectivas de sumo interesse para o desenvolvimento de propostas pedagógicas e didáticas baseadas em dinâmicas de colaboração e cooperaçáo. (COLL; MONEREO, 2010, p. 36).

A terceira fase da Internet é denominada Web 3.0 ou Web semântica. Seu uso transformaria a Internet em um espaço no qual a informação passaria a ser compreensível e não apenas localizável e se anunciaria como uma base de dados global capaz de proporcionar recomendaçóes personalizadas para os diferentes usuários. (COLL; MONEREO, 2010, p. 37).

De forma sintética, os três estágios podem ser resumidos no quadro abaixo.

Quadro 1 - Evolução da Internet

\begin{tabular}{|l|l|l|l|}
\hline Linguagem & \multicolumn{1}{|c|}{ Web 1.0 } & \multicolumn{1}{|c|}{ Web 2.0 } & \multicolumn{1}{c|}{ Web 3.0 } \\
\hline Metáfora & "pontocom” & puzzle & "sistema nervoso" \\
\hline Descrição & Rede de documentos & Rede social & Rede semântica \\
\hline $\begin{array}{l}\text { Função } \\
\text { principal }\end{array}$ & $\begin{array}{l}\text { Repositório de informa- } \\
\text { ção estática }\end{array}$ & $\begin{array}{l}\text { Criação e difusão de in- } \\
\text { formação dinâmica (con- } \\
\text { tinuadamente atualizável } \\
\text { e combinável) }\end{array}$ & $\begin{array}{l}\text { Respostas a informaçóes } \\
\text { personalizadas a partir de } \\
\text { perguntas e buscas }\end{array}$ \\
\hline $\begin{array}{l}\text { Usuários e } \\
\text { papéis }\end{array}$ & $\begin{array}{l}\text { O professor seleciona e e } \\
\text { administra a informação } \\
\text { para ser consultada pelos } \\
\text { alunos }\end{array}$ & $\begin{array}{l}\text { O professor e os alunos } \\
\text { selecionam, administram } \\
\text { e trocam informação, es- } \\
\text { tabelecendo dinâmicas de } \\
\text { colaboraçáo e cooperaçáo. }\end{array}$ & $\begin{array}{l}\text { Presença de agentes artifi- } \\
\text { ciais. O computador sele- } \\
\text { Professor e alunos são con- } \\
\text { sumidores e produtores. }\end{array}$ \\
\hline
\end{tabular}

Fonte: Adaptado do original de Coll e Monereo (2010, p. 38).

A Internet possibilita cada vez mais uma apropriação crescente de recursos, o que quer dizer, do ponto de vista do usuário, uma incorporação maior de transformaçôes em seu cotidiano, o que não necessariamente é refletido em suas práticas educacionais. 
No que se refere às TIC, as transformaçóes das últimas décadas tiveram seu impacto no ensino e aprendizagem de línguas estrangeiras pela quantidade de recursos disponíveis em sites, aplicativos de celulares ou tablets, canais de televisão e emissoras de rádio on-line com exercícios, acesso a dicionários, documentos de áudio, vídeo e texto, jogos lúdicos, quizz culturais, grupos de discussão em redes sociais, hipertextos relacionados a uma ou mais áreas de conhecimento e inúmeros outros recursos que, ao serem integrados às práticas educacionais, possibilitam uma ampliação das formas de ensinar e aprender. Há, sem dúvida nenhuma, múltiplos espaços de imersão linguística e cultural na língua estrangeira na Internet e nas TIC.

O que a tecnologia traz hoje é a integração de todos os espaços e tempos. O ensinar e o aprender acontecem em uma interligação simbólica, profunda e constante entre os chamados mundo físico e digital. Não são dois mundos ou espaços, mas um espaço estendido, uma sala de aula ampliada, que se mescla, hibridiza constantemente. (BACICH; TANZI NETO; TREVISANI, 2015, p. 39).

Sintetizando, as TIC e a Internet podem, potencialmente, favorecer o ensino e aprendizagem, no nosso caso, em línguas estrangeiras pelas seguintes razóes:

- Acesso a diversas informaçóes e documentos orais e escritos autênticos;

- Imersão em situaçóes autênticas de interação (blogs, sites, fóruns, redes sociais, materiais multimídias, softwares, aplicativos, entre outros);

- Acesso a novos recursos gratuitos são continuadamente disponibilizados;

- Acesso a espaços virtuais de comunicação on-line;

- Possibilidade de renovação do ensino e da aprendizagem de línguas por meio de novas experiências - transformaçóes dos cenários educacionais tradicionais (COLL; MAURI; ONRUBIA, 2010);

- Acesso a recursos que permitem criar espaços de formação inicial e continuada de professores para discussão sobre a utilização das TIC e Internet e concepçóes de ensino e aprendizagem a elas vinculadas;

- Possibilidade de criar ambientes virtuais de aprendizagem;

- Criação de novas práticas de aprendizagem marcadas pela interação, colaboração, cooperação e difusão do conhecimento.

No contexto de formação de professores de línguas interessa-nos estudar as modalidades de ensino decorrentes de todas estas transformaçóes. Isto é determinante para a formação reflexivo-crítica do aluno, que poderá compreender como pode ser concebida sua aula presencial e/ou virtual. É a tecnologia a serviço da aprendizagem e não o contrário.

A primeira modalidade de ensino e aprendizagem é a que associa ou integra ao contexto presencial, o uso das TIC ou de um ambiente virtual. Neste caso, a modalidade 
de curso descrita é caracterizada como sendo extensão da sala de aula presencial ao virtual, significando, em termos práticos, um acréscimo de carga horária à disciplina presencial.

A correspondência entre o presencial e o virtual se dá pela articulação de conteúdos e atividades, pelo paralelismo entre os dois espaços, a combinação de tarefas bem definidas com roteiros dirigidos e, em geral, com uma correspondência de calendário, ou seja, para cada conteúdo trabalhado em sala há uma atividade no ambiente virtual a ser feita. O professor preserva, assim, as especificidades dos espaços para assegurar o que está acostumado a fazer em suas práticas educacionais e para que o aluno não confunda $o$ que pode trazer do virtual para o presencial e o que é específico da sala de aula.

Esta modalidade náo "desprende" o presencial do virtual e é a que parece ser a mais simples de desenvolver e aplicar em contextos escolares/acadêmicos. A preservaçáo do presencial assegura ao professor uma dinâmica de aula que ele conhece, não altera sua prática no que se refere à interação com todos, à observação de cada aluno, seu ritmo de aprendizagem. No entanto, é a mais complicada de gerenciar, pois o professor acumula a função de gestor do ambiente e de tutor e avaliador dos alunos. Sua responsabilidade é de conceber, publicar, informar, receber, analisar, corrigir, avaliar e redigir feedbacks para às tarefas desenvolvidas.

A segunda modalidade de ensino é denominada formação mixta ou blended learning ou híbrida que se caracteriza pela combinação de atividades presenciais com outras realizadas a distância. Neste caso, não há alteração da carga horária total do curso; o que ocorre é uma divisão da carga horária entre o presencial e o virtual, mesclando "[...] momentos em que o aluno estuda os conteúdos e instruções usando recursos on-line, e outros em que o ensino ocorre em uma sala de aula, podendo interagir com outros alunos e com o professor" (VALENTE, 2014, p. 84).

Segundo o autor, o aluno tem à sua disposição no contexto on-line atividades específicas propostas pelo professor que devem ser realizadas fora da sala de aula. $\mathrm{O}$ aluno é responsável pela gestão do tempo, dos procedimentos que irá usar para realizálas dentro do próprio ambiente. Com o acompanhamento do professor, pretende-se que o aprendizado se torne mais eficiente, interessante e personalizado por meio de abordagens pedagógicas variadas na medida em que as atividades têm objetivos e conteúdos específicos que podem estar articulados de forma síncrona ou assíncrona, consecutiva ou simultânea.

Para Moran (2015, p. 42), a modalidade híbrida dá prioridade ao desenvolvimento “[...] de competências e metodologias ativas, personalização e colaboração, com tecnologias digitais. O currículo é mais flexível, com tempos e espaços integrados, combinados, presenciais e virtuais".

É fundamental ressaltar que, no ambiente virtual, o aluno deve desenvolver uma participação mais autônoma, conhecendo bem o ambiente onde as atividades serão realizadas, assim como as ferramentas necessárias para sua execução (NISSEN, 2014). 
A quarta modalidade de ensino e aprendizagem é a sala invertida (fipped classroom) que segundo Valente (2014, p. 79, grifo nosso) é

[...] uma modalidade de e-learning na qual o conteúdo e as instruçóes são estudados on-line antes de o aluno frequentar a sala de aula, que agora passa a ser o local para trabalhar os conteúdos já estudados, realizando atividades práticas como resolução de problemas e projetos, discussão em grupo, laboratórios etc.

Esta modalidade é a que mais altera a cultura de aprendizagem que temos hoje, na medida em que o aluno tem parte fundamental e essencial para o andamento do curso ou disciplina. A preparação de trabalhos, atividades de caráter teórico e prático é feita pelo aluno e é anterior à aula e pode ocorrer em encontros presenciais pontuais ou no ambiente virtual.

O que é interessante nesta modalidade é a mobilização de conhecimentos prévios que o aluno deve acionar para realizar a atividade, a articulaçáo com novos conteúdos relacionados aos temas que são estudados para sua apresentação. Sua participação nas atividades é ativa e determinante para que os objetivos sejam atingidos. Nesta modalidade, o papel do professor é também ativo, mas de outra natureza, pois há uma construção compartilhada entre professor e alunos cuja mediação pode ser alternada, de forma a não centralizar no professor.

Para Moran (2015, p. 40), a aula invertida tem como característica “[...] concentrar no ambiente virtual aquilo que é informação básica e deixar para a sala de aula as atividades mais criativas e supervisionadas".

Segundo o autor, o planejamento da aula pode ser feito da seguinte maneira:

O docente propõe o estudo de um determinado tema, e o aluno procura as informaçôes básicas na internet, assiste a vídeos e animaçóes e lê os textos que estão disponíveis na web ou na biblioteca da escola. O passo seguinte é fazer uma avaliação, pedindo que a turma responda a três ou quatro questôes sobre o assunto, para diagnosticar o que foi aprendido e os pontos que necessitam de ajuda. (MORAN, 2015, p. 40).

O papel do professor e do aluno muda substancialmente na medida em que há uma nova dinâmica que se instala, à qual não estâo habituados. $\mathrm{O}$ compartilhamento de responsabilidades, as tarefas distribuídas, as orientaçóes para os alunos que tiveram alguma dificuldade em realizá-las e o trabalho em grupo na sala de aula para a articulação do que foi pesquisado, discutido e que deve ser sistematizado, toma outra dimensão. $\mathrm{O}$ aprendizado combina colaboração do coletivo para a realização de um projeto, cooperação entre alunos para o cumprimento de tarefas específicas e personalização dos percursos individuais.

Segundo Moran (2015), as TIC podem favorecer a prática da sala de invertida, pois recursos são utilizados para auxiliar o desenvolvimento das atividades. 
Para o autor, é importante ressaltar que para a implementação desta modalidade, seria necessária uma reorganização do currículo, uma flexibilização de conteúdos, a variação de metodologias, dos tempos e espaços em que a aprendizagem poderia ocorrer.

A partir dos elementos levantados, passamos, na próxima seção, ao contexto de nosso estudo, visando depreender da nossa experiência, o que as práticas na Plataforma Moodle podem indicar de proximidade com as modalidades de ensino.

\section{Problematizando o uso da Plataforma Moodle como extensão da sala de aula presencial}

Os cursos de Letras - Licenciatura no Brasil, o ensino e aprendizagem de línguas nas universidades brasileiras para formação de professores é realizado na modalidade de cursos presenciais. A prática oral da língua e a preservação das relaçóes na sala de aula, além da ausência de uma estrutura que permita a criação de cursos a distância em universidades públicas de todo o país são umas das razões que fazem predominar esta modalidade (SANTOS, 2015).

No que se refere ao Curso de Letras Licenciatura Francês/Português da Universidade de São Paulo, a integração da Plataforma Moodle às disciplinas que são ministradas na Faculdade de Filosofia, Letras e Ciências Humanas começou a ser feita em 2008. As disciplinas "Aquisição e aprendizagem do Francês como Língua Estrangeira" e "Atividades de Estágio em francês" estão sob minha responsabilidade, são oferecidas presencialmente aos alunos da Habilitação Licenciatura em Francês e em Francês/ Português e a integração do Moodle representa um aumento de trabalho para o curso presencial.

Os alunos inscritos nas disciplinas estáo no $5^{\circ}$ ou $7^{\circ}$ semestre do Curso de Letras e em termos dos conhecimentos em francês, seu nível de língua é equivalente ao B1 ou B2 do Cadre commun européen de référence pour les langues (CECR), tendo cursado, nesse momento, 360 horas de língua francesa.

Do grupo de alunos, 20\% estão engajados em projetos de Iniciação Científica (IC) cujos temas gerais estão relacionados ao ensino-aprendizagem da língua. Estes alunos trazem contribuiçóes significativas para o grupo, pois seus trabalhos promovem reflexóes sobre as pesquisas nos contextos nos quais estão sendo desenvolvidas (Escolas de línguas, Centros de Línguas e Cursos de Extensão).

A maior parte do grupo de alunos (80\%) está em formação e ainda não têm claro quais são as possibilidades de ensino da língua francesa, quais práticas pedagógicas são realizadas e, sobretudo, o que as TIC podem contribuir para o ensino-aprendizagem de línguas estrangeiras.

Em se tratando da Plataforma Moodle (software livre), a partir de dados obtidos do Center for Learning \& Performance Technologies (COLL; MONEREO, 2010, p. 27), trata-se do ambiente que ocupa o $13^{\circ}$ lugar de utilizaçáo para a aprendizagem e, no nosso caso, a plataforma de apoio às disciplinas presenciais, conhecida pelos alunos 
(100\%) por meio de várias disciplinas da grade curricular que a utilizam somente para estocagem de textos e canal de informação, ou seja, como espaço de aprendizagem, a extensão das disciplinas de didática para a plataforma é completamente nova.

A disciplina "Aquisição e aprendizagem do Francês como Língua Estrangeira" é mais teórica e os alunos realizam atividades de grupo e seminários nas aulas presenciais, tendo no Moodle um espaço importante para consulta a documentos, vídeos inseridos no ambiente relacionados aos temas das aulas, fóruns de discussão, entre outras atividades. $\mathrm{Na}$ disciplina "Atividades de Estágio em francês", os alunos, individualmente, realizam projetos relacionados ao ensino e aprendizagem da língua francesa a partir de um tema escolhido, o que determina uma dinâmica particular de apoio e supervisão do professor que ocorre no ambiente virtual.

Quadro 2 - Disciplinas e ementas disciplinas de didática da FFLCH-USP

\begin{tabular}{|l|l|}
\hline \multicolumn{1}{|c|}{ Disciplina } & \multicolumn{1}{c|}{ Ementa da disciplina } \\
\hline $\begin{array}{l}\text { Aquisição } \\
\text { e aprendizagem } \\
\text { do FLE }\end{array}$ & $\begin{array}{l}\text { Embasar teórico-metodologicamente o aluno, capacitando-o para a análise } \\
\text { crítica de propostas didático-pedagógicas relativas ao ensino e à aqui- } \\
\text { siçáo/aprendizagem do francês como língua estrangeira, em diferentes } \\
\text { contextos. }\end{array}$ \\
\hline $\begin{array}{l}\text { Atividades de } \\
\text { estágio - Francês }\end{array}$ & $\begin{array}{l}\text { Propiciar aos estudantes a oportunidade de realizar atividades práticas e } \\
\text { projetos relativos ao ensino e aprendizagem de línguas (materna e/ou } \\
\text { estrangeira. Discutir com os alunos estratégias que lhes permitam atuar } \\
\text { como professor/educador, solidificando sua formaçáo pedagógica, o que } \\
\text { lhes possibilitará desenvolver eficientemente atividades de oralidade, leitura } \\
\text { e escrita. }\end{array}$ \\
\hline
\end{tabular}

Fonte: Portal da USP².

A inclusão do Moodle como extensão da sala de aula presencial se deu pelas seguintes razóes:

- É neste contexto que os alunos podem desenvolver atividades que os levem a refletir como futuros professores como utilizar as TIC para o ensino, pois podem vivenciar experiências concretas no ambiente virtual.

- O ambiente virtual é totalmente concebido na língua estrangeira, neste caso o francês, o que determina uma situação de imersão mais vezes na semana, além da sala presencial.

- O gerenciamento do tempo é de responsabilidade do aluno.

2 Disponível em: <https://uspdigital.usp.br/jupiterweb/jupDisciplina?sgldis=0800006\&verdis=1>. Acesso em: 3 out. 2016. 
- O uso das ferramentas permite um maior conhecimento do ambiente.

- O aluno realiza as atividades como aluno do curso e observa, ao mesmo tempo, como o espaço é concebido desde sua organização até as escolhas de atividades e ferramentas, o que possibilita reflexōes sobre a atuação do professor na plataforma.

É importante ressaltar que nesta modalidade, há uma sobrecarga para o docente na medida em que há uma correspondência estreita de conteúdos dados entre o presencial e o virtual durante todo o semestre e é ele o responsável por conceber todo o ambiente. Isto determina uma escolha de ferramentas já que não é possível explorar todo o potencial da plataforma.

Assim, o primeiro aspecto que chama a atenção dos alunos é a abertura da sala, ou seja, como o ambiente é organizado e quais características devem ser consideradas.

Ressaltamos os seguintes aspectos:

- Aspectos visuais: o Moodle permite que a sala seja organizada por semanas (calendário), o que representa a abertura de 15 aulas que correspondem ao número dos encontros presenciais ou uma organização em tópicos, por temas. Para cada uma das possibilidades há imagens estáticas ou móveis para ilustrar a sala virtual;

- Abertura da semana ou do tópico: publicação na primeira aula de uma mensagem de boas-vindas para o início do curso e para as outras de objetivos e orientaçóes referentes às atividades programadas;

- Canal de comunicação do professor para o aluno: envio de mensagens que são publicadas e entram diretamente na caixa postal do aluno. Isto é feito pelo calendário de notícias. $\mathrm{O}$ aluno não utilizou o Moodle para envio de mensagens ao professor. Nesta modalidade de curso, a opção de comunicação entre aluno(s) e professor se deu na sala de aula presencial.

Em relação às atividades, os quadros abaixo apresentam o que foi solicitado aos alunos $^{3}$, o tipo de atividade na plataforma, a ferramenta utilizada e suas características.

3 As disciplinas são ministradas desde 2008 no Moodle e as ferramentas utilizadas predominantes são as apresentadas nos quadros. Para nossa análise foram recuperados os dados dos 4 últimos semestres. 
Quadro 3 - Disciplina Aquisição e aprendizagem do Francês

\begin{tabular}{|c|c|c|c|}
\hline Disciplina & $\begin{array}{l}\text { Tipo de } \\
\text { atividade }\end{array}$ & $\begin{array}{c}\text { Ferramentas utilizadas } \\
\text { no Moodle }\end{array}$ & Característica \\
\hline \multirow{6}{*}{$\begin{array}{l}\text { Aquisição e } \\
\text { aprendizagem } \\
\text { do FLE } \\
1^{\circ} \text { semestre de } \\
2014 \text { e } 2015\end{array}$} & $\begin{array}{l}\text { Compreensão } \\
\text { oral ou escrita }\end{array}$ & $\begin{array}{l}\text { Inserção de vídeos ou } \\
\text { textos diretamente na sala }\end{array}$ & Acesso direto no ambiente \\
\hline & \multirow[t]{4}{*}{ Produção } & Tarefa & $\begin{array}{l}\text { Produção de textos com feed-back } \\
\text { individual do professor para o } \\
\text { aluno }\end{array}$ \\
\hline & & Questionário & $\begin{array}{l}\text { Atividade de múltipla escolha } \\
\text { ou questáo aberta utilizada para } \\
\text { síntese de uma temática }\end{array}$ \\
\hline & & Glossário & $\begin{array}{l}\text { Inclusão de conceitos em } \\
\text { didática de línguas }\end{array}$ \\
\hline & & Portfólio & $\begin{array}{l}\text { Elaboração individual com uso } \\
\text { das TIC }\end{array}$ \\
\hline & Interação & Fórum & $\begin{array}{l}\text { Interaçóes em língua francesa } \\
\text { sobre temas relacionados ao que } \\
\text { foi visto no presencial }\end{array}$ \\
\hline
\end{tabular}

Fonte: Elaboração própria.

Quadro 4-Disciplina Atividades de estágio em francês

\begin{tabular}{|l|l|l|l|}
\hline \multicolumn{1}{|c|}{ Disciplina } & $\begin{array}{c}\text { Tipo de } \\
\text { atividade }\end{array}$ & $\begin{array}{l}\text { Ferramentas utilizadas } \\
\text { no Moodle }\end{array}$ & \multicolumn{1}{|c|}{ Característica } \\
\hline $\begin{array}{l}\text { Atividades de } \\
\text { estágio em } \\
\text { francês } \\
2^{\circ} \text { sem de } \\
2014 \text { e } 2015\end{array}$ & Produçáo & Tarefa & $\begin{array}{l}\text { Produçáo de textos com feed-back } \\
\text { individual do professor para o aluno }\end{array}$ \\
\cline { 3 - 4 } & \multirow{2}{*}{ Interaçáo } & Fuestionário & $\begin{array}{l}\text { Atividade de múltipla escolha ou } \\
\text { questáo aberta utilizada para síntese de } \\
\text { uma temática }\end{array}$ \\
\cline { 3 - 4 } & Portfólio & Elaboraçáo individual com uso das TIC \\
\cline { 3 - 4 } & Diálogo & $\begin{array}{l}\text { Interaçóes em língua francesa sobre } \\
\text { temas relacionados ao que foi visto no } \\
\text { presencial }\end{array}$ \\
\hline
\end{tabular}

Fonte: Elaboração própria. 
Os dados obtidos:

- a organização das salas nos semestres foi alternada entre semanal e por tópicos;

- $100 \%$ das atividades de produção solicitadas pela ferramenta tarefa foram realizadas.

- $80 \%$ dos alunos completaram o questionário - a atividade síntese no Moodle ficou semelhante ao que foi comentado na sala de aula presencial. A ferramenta auxiliou na organização do conteúdo. O feedback das respostas foi dado para todos no presencial;

- a ferramenta glossário foi utilizada somente na $1^{\text {a }}$ disciplina com o objetivo de criar um glossário de didática a partir das leituras teóricas desenvolvidas. Houve $30 \%$ dos alunos que publicaram itens neste espaço do Moodle;

- o fórum foi proposto duas vezes por semestre relacionado a uma temática tratada em sala de aula. A participação dos alunos foi de 50\%. Após uma intervenção do professor subiu para $60 \%$.

- a ferramenta diálogo foi utilizada somente na $2^{\text {a }}$ disciplina e obteve uma boa resposta dos alunos (100\%), pois a interação se deu de forma individual e relacionada ao projeto específico que o aluno deveria realizar e entregar ao final do semestre.

- Duas atividades dirigidas foram feitas em cada semestre, a partir de um roteiro a ser seguido fora do ambiente. $\mathrm{O}$ envio das atividades foi feito pela ferramenta tarefa.

O que podemos depreender destes dados e da modalidade de curso extensão do presencial ao virtual?

No que se refere à organização da sala, o formato de tópicos é mais interessante na medida em que há uma escolha dos temas mais relevantes e prioriza-se no ambiente o conteúdo estudado e não a progressão cronológica do semestre. Foram incluídos arquivos de textos para um aprofundamento da temática, assegurando para o aluno a constituição de um quadro de referências teóricas que pode ser utilizado em autonomia.

O índice de $100 \%$ de tarefas entregues está relacionado a uma lógica presencial, pois há atribuição de nota e o reforço ao trabalho individual do aluno. É a ferramenta mais usada, pois se assegura o recebimento da atividade. $\mathrm{O}$ grau de interaçáo é unilateral (do professor para o aluno) e se dá somente no feedback, apesar de ser possível configurar para receber rascunhos antes da entrega final. Isto não é aplicado, pois o professor duplicaria seu trabalho de correção.

Com a ferramenta diálogo, a interação é mais clara e viável, pois se trata de um trabalho de supervisão e orientação em cima de um projeto concreto que é desenvolvido ao longo do semestre. Esta ferramenta em um curso híbrido poderia ser melhor aproveitada na medida em que o aluno ocuparia uma parte da carga horária do curso 
para realizar as pesquisas e elaboração de novas versóes de seu trabalho. Esta carga horária estaria dentro do número de horas do curso.

A ferramenta questionário demandou do professor a elaboração de questôes que poderiam dirigir a síntese do tema. A questão da baixa participação foi relacionada à ausência de uma nota e ao fato de, no presencial, os mesmos pontos terem sido retomados, o que para o aluno que tomou nota na aula, significaria duplicar um trabalho no virtual.

Para os fóruns, o espaço por excelência de maior interação, a participação, em geral, é oscilante e, neste caso, dependeu de uma intervenção direta do professor no presencial "Pessoal, aguardo vocês no fórum". As trocas de mensagens mediadas pelo professor asseguram com maior facilidade a percepçáo do espaço como sala virtual e aí é possível ver a reação dos alunos. O que é problemático é não ficar claro que o aluno também pode ser mediador, alimentando o fórum com questionamentos dirigidos ao coletivo.

As TIC no Moodle ficaram restritas aos vídeos, inseridos pelo professor e ao Portfólio, produção final que resultou em trabalhos espaços on-line e impressos.

Nestes semestres foram introduzidas as atividades dirigidas. O professor elegeu um tema, definiu um roteiro de estudo e pesquisa para os alunos que saíram do espaço presencial, ou seja, usaram da carga horária da semana para buscar referências em outros espaços e fontes para a realização da tarefa. Podemos considerar que esta atividade aproxima-se de uma lógica híbrida, mas como é pontual não é transparente para o aluno apreender esta lógica. Para o professor, a experiência mostrou que é possível aumentar a quantidade de atividades dirigidas, detalhando as etapas que devem ser seguidas, com ampliação de fontes, com associação de recursos TIC, como por exemplo, um diário digital de relato da realizaçáo da atividade. Isto proporcionaria uma reflexão metacognitiva de suma importância no processo de formação dos alunos.

\section{Concluindo}

Do estudo reflexivo-crítico que realizamos, algumas conclusóes podem ser formuladas, indicando caminhos para a pesquisa com as TIC e Internet, nas modalidades de ensino do presencial ao virtual e híbrida.

O primeiro ponto é trabalhar para a descentralização do papel do professor e o crescimento do papel do aluno, favorecendo sua autonomia como construtor de conhecimentos a serem compartilhados. O Moodle, como foi descrito, funcionou muito mais como um canal funcional de comunicação entre professor e alunos, espelho do presencial, náo ficando clara intenção de mudanças nas culturas de ensino e aprendizagem.

Além disso, nos parece importante repertoriar as experiências que estão sendo realizadas em diferentes instituiçôes visando ao compartilhamento de dificuldades e soluçóes encontradas. 
Com os avanços rápidos das TIC e da Internet, novas práticas podem surgir e configurar novos aprendizados, conhecimentos e modalidades de curso que respondam mais às necessidades de nosso tempo. As mudanças podem caminhar para a valorização da atuação do aluno em autonomia, a capacidade de interação em diferentes espaços, o desenvolvimento da colaboração, cooperação e difusão de conhecimentos e a integração das TIC e da Internet para a expansão do aprendizado do aluno além das quatro paredes.

\section{PROBLEMATIZING TEACHING AND LEARNING PRACTICES ON MOODLE PLATFORM: APPROACHES WITH HYBRID METHODOLOGY}

- ABSTRACT: This chapter aims to accomplish a reflective-critical study about Moodle teaching experiences in the disciplines of the Didactics of the undergraduate degree in French and Portuguese at the University of São Paulo. We will present the theoretical foundations that support this study, more particularly, the transformations brought by Information and Communication Technologies and Internet and the consequences in the learning culture (COLL; MONEREO, 2010; KENSKI, 2008). We will also discuss the general framework of teaching methods brought by these changes in the teaching and learning approaches, specifically in hybrid modality (COLL; MONEREO, 2010; VALENTE, 2014; BACICH et al., 2015). Afterwards, we will describe the Moodle activities and discuss the limits and possibilities generated by this study in relation to other modalities. Finally, we will propose some aspects that could guide other studies and research in this area of expertise.

- KEYWORDS: Technologies. Virtual learning modalities. Moodle. Hybrid teaching.

\section{REFERÊNCIAS}

BACICH, L.; TANZI NETO, A.; TREVISANI, F. de M. (Org.). Ensino hibrido: personalização e tecnologia na educação. Porto Alegre: Penso, 2015.

COLL, C.; MONEREO, C. (Org.). Psicologia da educaçáo virtual: aprender e ensinar com as tecnologias da informação e da comunicação. Porto Alegre: Artmed, 2010.

COLL, C.; MAURI, T.; ONRUBIA, J. A incorporação das tecnologias da informação e da comunicação na educação: do projeto técnico-pedagógico às práticas de uso. In: COLL, C.; MONEREO, C. (Org.). Psicologia da educaçáo virtual: aprender e ensinar com as tecnologias da informação e da comunicação. Porto Alegre: Artmed, 2010. p.66-93.

KENSKI, V. M. Tecnologias e ensino presencial e a distância. Campinas: Papyrus, 2008.

LALUEZA, J. L.; CRESPO, I.; CAMPS, S. As tecnologias da informação e da comunicação e os processos de desenvolvimento e socialização. In: COLL, C.; MONEREO, C. (Org.). 
Psicologia da educaçáo virtual: aprender e ensinar com as tecnologias da informação e da comunicação. Porto Alegre: Artmed, 2010. p.47-65.

MORAN, J. Educação-híbrida: um conceito-chave para a educação, hoje. In: BACICH, L.; TANZI NETO, A.; TREVISANI, F. de M. (Org.). Ensino hibrido: personalização e tecnologia na educação. Porto Alegre: Penso, 2015. p. 27-45.

NISSEN, E. Les spécificités des formations hybrides en langues. Alsic: Apprentissage des Langues et Système d'Information et de Communication, Strasbourg, v.17, 2014. Disponível em: <http://alsic.revues.org/2773>. Acesso em: 27 set. 2016.

\section{SANTOS, V. Sensibilização de futuros professores para a docência on-line em Educação a}

Distância no ensino de leitura de textos digitais em língua francesa: o Moodle como espaço de formação inicial. 2015. 360f. Dissertação (Mestrado em Língua e Literatura Francesa) Faculdade de Filosofia, Letras e Ciências Humanas, Universidade de São Paulo, São Paulo, 2015. Disponível em: <http://www.teses.usp.br/teses/disponiveis/8/8146/tde-17092015121539>. Acesso em: 27 set. 2016.

VALENTE, J. A. Blended learning e as mudanças no ensino superior: a proposta da sala de aula invertida. Educar em Revista, Curitiba, n. 4, ed. esp., p. 79-97, 2014.

Recebido em 12/07/2016

Aprovado em 11/08/2016 
